\title{
A Brief Introduction of Physics of Glaciers and Avalanches
}

\author{
Min Raj Lamsal \\ Department of Physics, Prithvi Narayan Campus, Pokhara \\ Correspondence:min_lamsal@yahoo.com
}

\begin{abstract}
This article deals with the introduction and types of snow as well as glaciers and the basic mechanism of glacial movement and avalanches which is one of the most burning issues on the context of our Himalayan region. Because of such avalanches, which are more frequently occurring in the Himalayan region, many animals, plants, farmer's small buildings etc. are being carried away and the death of many people is being caused which is due to lack of knowledge of the factors responsible for avalanche occurrence. This article also deals with such factors and the safest way to deal with the avalanche control.
\end{abstract}

Keywords: snow, glaciers, glacial movement, erosion, deposition, avalanche, avalanche control.

\section{Introduction}

The activities of men take place within the physical environment and the physical environment is considerably affected by these activities. Physiography included the study of the atmosphere, water and landforms of the earth surface. Physical geography brings together and unifies several branches of natural science including physics for the purpose of understanding the relationship of man to his physical environment.

The presence of snow is fundamental at high altitudes and provides the essential ingredient for the development of glaciers and avalanches. These three interrelated phenomena, which contribute much to the distinctiveness of mountain landscapes,offer a considerable challenge to the inhabitants, both plant and animal, of these regions. Snow covered peaks like Machhapuchhre are one of nature's most awesome and beautiful sights which have been a central theme in the art, literature and music all over the world.

When the temperature of the air falls below dew point, water vapour present in the atmospheric air condenses due to which weather exhibits many phenomena like the formation of dews, hail, cloud, rain, fog, mist, hoarfrost and snow. When the cloud passes through a very cold region, the water drops freeze and falls in the form of snow and Hail. Snow fall in all hill stations because of very low temperature in winter. Hails are caused due to the freezing of rain drops in the atmosphere. Hails are of different sizes and hard whereas snow is quite soft.

\section{Snow}

Snow is precipitation in the solid form that originates from freezing of super cooled water around tiny nuclei of foreign maters, especially clay minerals, in the air. Once formed, snow crystals are subject to continual change during falling and accumulation on the ground, until it eventually melts and returns to the sea. Snow received at the summits of the mountains is often quite different from that received on middle slopes of ranges. The principal forms of snow crystals are plate, stellar crystal,column, needle, spatial dendrite, capped column, irregular crystal, grauppel, ice pellet and hail

Snow may form in the atmosphere at any latitude, but in order to maintain its identity it must fall to the earth in an area with sufficiently low temperature to preserve it. Most fallen snow melts within a few days or months, depending upon the amount received and climatic conditions. The exact behavior of fallen snow depends upon its temperature, moisture content, internal pressures and age. Periodic melting and refreezing due to regelation of the snow also produces increased densification. The snow may now be as much as 15 times heavier than when it first fell and it is well on its way toward becoming glacial ice. Avalanches may transport large masses of snow to valley bottoms where, they may persist for several years. Similarly mountain glaciers occupy sheltered topographic sites and receive grater accumulations from drifting snow and avalanches than do the surrounding slopes. 


\section{Glaciers}

Glaciers are river masses of ice, which under the influence of gravity; flow out from the snow fields where they originate. In other words, glacier is a mass of ice which moves slowly down a valley from above the snowline towards the sea under the force of gravity. According to the dictionary of geography a glacier is a mass of snow and ice that moves slowly over the land away from its place of accumulation. Glacier, an enduring accumulation of ice, snow, water, rock and sediment that moves under the influence of gravity. Glaciers form where the temperature is low enough to allow falling snow to accumulate and slowly transform into ice. This accumulation is most common in the polar regions, but can also occur at high altitudes on mountains even near the equator. Glaciers are complex systems that grow and shrink in response to climate. At the present, glacier ice covers about 15 million sq.km. Or $10 \%$ of earth's land area. A glacier is a mass of moving ice created by the accumulation of snow. The transformation of snow into ice is a process of densification and expulsion of air. This is accomplished by sublimation, melting and refreezing and compaction. Sublimation, melting and refreezing are most important when snow is still near the surface and compaction becomes more important after the snow has been buried under successive annual accumulations. In the simplest terms, all that is required for a glacier to form is for more snow to fall than melts. Once formed, a glacier responds to and reflects changing climatic conditions. Glacial movement is determined by the thickness of the ice, its temperature, the steepness of the glacial surface and the configuration of the underlying and confining topography.

\section{Types of Glaciers}

Glaciers occur in many different forms and locations, from the big ice sheet that covers the entire continent of Antarctica to the small valley glaciers that are present in many parts of the world. They are generally divided into several categories depending on their size and location. Glaciers categorized by size include ice fields, ice caps, and ice sheets.

Glaciers categorized by locations include continental, alpine, valley, and piedmont glaciers.

\section{Glacial Movement}

Glaciers wax and wane not only with long -term climate change but also on a seasonal basis. Snow falls in winter, accumulates, and slowly turns to ice when it is compressed by additional snow loads. In summer the upper snow layers thaw and meltwater runs off; this loss is called ablation. The glacier's mass balance or budget then turns from positive to negative as it loses mass. The balance is neutral or in equilibrium from year to year if the glacier does not experience any mass loss or gain. A complex series of processes determines the glacier's health.

Glaciers are thought to move through two basic mechanisms - plastic flow and basal sliding. Glaciers flow much like a viscous liquid, but in recent years it has been realized that ice behaves more like a polycrystalline solid where there is deformation due to flow or creep, as in the creep of metals. Ice is much weaker than most crystalline solids and deforms easily through the action of gravity on its mass. The processes involved in plastic flow are still not completely agreed upon, but the favored theory that of intragranular yielding, says that the ice crystals yield to shear stress by gliding over one another along basal planes within the lattices of the ice crystals. The individual ice crystals should become internally elongated, but since no such deformation of crystals is found in glaciers, a progressive recrystallization apparently accompanies the deformation. The flow is largely a result of directional shear stress, so the ice is equally plastic throughout. The other major mechanism involved in glacier movement is that of basal sliding, which involves the slippage of ice over the rock surface at its base. The processes involved are even less well understood than those of plastic flow, since the base of a glacier is inaccessible to direct observation. An important factor is the temperature of the ice at the base and the presence of water to serve as a lubricant. Water may be released when ice reaches the pressure melting point. This happens when an obstacle is encountered during glacial movement; the ice is compressed on the upstream side of the obstruction and the increased pressure causes melting. The meltwater then flows around the obstacle and refreezes to the downstream side where the pressure is less. The process is maintained by the latent heat of fusion which is transmitted through conduction from the freezing area upglacier to the melting area, where 
it helps maintain the melting.

Although ice is normally brittle, it can flow under pressure. The speed at which glaciers move depends on a number of factors, including their temperature, the amount of meltwater at the bottom of the ice, the steepness of the slope, and the nature of rock surface over which they move. The big ice sheets move by internal deformation as ices building up in the middle forces the edge expand. Valley glaciers move by sliding over their rock beds. Friction with the ground produces heat that in turn melts ice and helps to lubricate the sliding. Measurements of glacier movement indicate that they move fastest in the middle of the glacier where the ice is the thickest. Valley glaciers typically sustain velocities of 30 to $60 \mathrm{~cm}$ per day or 100 to 200 $\mathrm{m}$ per year, but some can reach speeds of 3 to $6 \mathrm{~m}$ per day. On the large outlet glaciers in Greenland velocities of over $30 \mathrm{~m}$ per day have been measured. Short-term advances in so called galloping or surging glaciers can reach $80 \mathrm{~m}$ per day.

\section{Glacial Erosion and Deposition}

When a glacier moves over an area, the ice undergoes plastic deformation to fill every nook and cranny. Movement at the ice-rock interface results in modification of the underlying surface through glacial erosion and transport. The primary processes are abrasion and plucking or quarrying. Glaciers typically gouge out U-shaped valleys. Glaciers sometimes create these valleys near the coast. When the ice retreats from these coastal valleys, it leaves behind fjords, narrow inlets flanked by steep mountains on either side. As glaciers move over bedrock they scrape and abrade its surface, producing fine-grained rock flour. Glaciers can also pluck away rocks up to boulder size and transport and deposit them along the margins of the glacier down in the valleys. The glaciers deposit these materials as till, sediment consisting of mud, sand, gravel, and boulders. Much of this material is deposited in long mounds called moraines. Lateral moraines are formed on each side of a valley glacier where abraded sediment and plucked rocks are deposited. These moraines are often preserved when glaciers melt and can indicate previous glacier heights. Medial moraines separate tributary glaciers that flow into a compound valley glacier. Terminal or end moraines mark the farthest distance down a valley that a glacier has reached in its advance.

\section{Glaciers and Climate Change}

Glaciers are very sensitive to climate change. Their size, life span, and history of growth and retreat all depend strongly on climate conditions. Since they are so sensitive to climatic changes they also serve as good indicators of change. A glacier's accumulation and ablation, or gain and loss of mass, are primarily dependent on temperature and precipitation, but also on solar radiation, humidity, and wind speed. Location, orientation, and exposure of the glacier are also important, particularly for the smaller valley glaciers. The energy budget or balance of a glacier's surface reflects how much heat energy is received or lost from a glacier and whether evaporation or melting can occur. The energy budget explains in quantitative terms what is termed the microclimate of a glacier. Many glaciologists believe that the current worldwide retreat of glaciers is influenced by global warming. They believe global warming is caused by the buildup of greenhouse gases in the atmosphere since humans began using fossil fuels during the Industrial Revolution. Higher average temperatures are causing glaciers to melt faster than they can be replenished by winter snows.

\section{Avalanches}

Avalanche is a sudden flow of a large mass of snow or ice down a slope or cliff sometimes at speeds exceeding $160 \mathrm{~km}$ per hour. Such flow can be destructive of life and property. Avalanches are most common on slopes exceeding 30 degree, frequently when a deep snow falls suddenly and does not have a chance to cohere, or when a thaw undercuts a blanket of older snow. Pelletlike snow ( grauppel) is also more prone to avalanche than a fall of ordinary snowflakes. Flows of wind-packed slabs of snow can be specially hazardous. Avalanches are set off by a combination of factors including temperature, shearing of creeping snow masses, and sudden vibrations including loud noises. Snow patrols in mountain areas reduce the hazard by detonating strategically placed explosives that cause smaller, less destructive flows. A landslide is a similar massive movement of rock and soil.

The sudden release and movement of vast amounts of snow down a mountainside can be an awe-inspiring phenomenon. The avalanche is one of the great destructive forces in nature and every bit the equal of the hurricane, the tornado, and the earthquake. 
Thousands of persons have perished in avalanches over the centuries. If mountains were heavily populated, the toll would be even higher. Untold numbers of avalanches occur every year but only a few are observed or recorded. With increasing population in mountains, however, the potential for avalanche damage increases markedly.

There are two principal types of avalanches-the loose snow avalanche and the slab avalanche. The loose snow avalanche is usually small and relatively harmless whereas a slab avalanche may involve large amount of snow and cause considerable destruction. The distinction between the two types is based on snow conditions at the point of origin, since a snow slide may lose its original identity by the time it reaches the valley below.

A mass of unstable snow perched on a mountain side is like a loaded gun, it awaits only the triggering action to set it off. The point of critical instability for avalanche release is reached when the component of force parallel to the slope exceeds the shear strength of the bond between the surface snow and the under layer. The weight builds up until it overcomes cohesion and the snow begins to slide. Warming of the snow usually decreases its internal cohesion, while lowering of the temperature retards settlement of the snow mass increases its brittleness, and may create an equally if not more unstable situation. A number of natural external factors can trigger an avalanche, example, the falling of an overhanging snow mass, a rock fall or even lumps of snow falling from tree branches.

There are two main causes of avalanches-snow and slopes. The favored slope angle is between 30-45 degree. Anything less than this doesn't create enough down slope stress while steeper slopes don't retain enough snow to cause large avalanches. Thus, the probability of avalanches increases with steeper slopes to a certain point and then decreases. Given the framework of mountainous terrain, snow and weather conditions are the critical factors in avalanche occurrence. There are ten main factors responsible for this which is given below;
1. old-snow depth
2. condition of the depth
3. new-snow depth
4. new-snow type
5. new-snow density
6. snowfall intensity
7. precipitation intensity 8 . settlement

9. wind

10. temperature

\section{Avalanche Control}

The safest way to deal with the avalanches is to avoid them but it is impossible in mountainous country like Nepal. There are two basic approaches to the control of avalanches-modification of terrain and modification of the snow. The first method is relatively effective but that is expensive and requires continual maintenance, whereas the second is much less expensive but must be applied repeatedly. Terrain modification consists of placing structures-walls, dams and wedges of various designs-either in the snow accumulation zone or immediately above the area to be protected.

The control of avalanches is expensive, however, and it will never be possible to tame the snowy torrents entirely. In the long run, the best defense is careful planning and location of activities to avoid areas of high avalanche danger.

\section{Conclusion}

Snow is the solid form of water which can be regarded as major part of water cycle. When snow gets deposited to form thick layer then it melts for which the physical phenomenon regelation is responsible and finally a glacier is formed. After the formation of glacier, it starts to move with different velocity depending upon the slope of the himalayan region. When it starts to move the effect of erosion becomes more significant due to the energy carried by it. Finally deposition of eroded material takes place due to decrease in its velocity with the change (decrease) in the slope of glaciers. So due to avalanche effect the large amount of destruction takes place for which human activities and global warming are also direcly or indirectly responsible in some extent except water cycle. The avalanche effect can be minimized by applying the knowledge of physics of physical priciples involved in it.

\section{References}

1. Glacier Microsoft Encarta, 2009. Microsoft Corporation, Redmond, WA.

2. http:// nsidc.org/glaciers

3. Lamsal M.R. et al., 2009. Themes of Physics, Koselee Prakashan, Nepal,

4. Larry Price, 1981. Mountain and Man, Colorado

5. M.S. Rao, 1991.Anmol's Dictionary of Geography, New Delhi, India. 